\title{
Tobacco Surveillance
}

National Cancer Institute

\section{Source}

National Cancer Institute. Tobacco Surveillance. NCI Thesaurus. Code C16176.

Surveillance to improve the capacity to identify and understand emerging disparities in tobacco use, particularly among at risk youth. (from The NCI Strategic Plan to Reduce Health Disparities) 